\title{
CLINICAL NEUROLOGY OF YESTERDAY, TODAY AND TOMORROW. SOME MID-CENTURY REFLECTIONS
}

\author{
G. H. Monnah-Krohn
}

Just as the central nervous system has a central and dominant position in the human body, so neurology should have by right a central position in medical science. This obvious point of view is gradually gaining ground. But it has not always been so and in many otherwise civilized countries neurology has not even yet come into its own.

In some countries like France clinical neurology has for a long time been regarded as a central discipline and the professorial chair of neurology - the chair of Charcot - has long been regarded as one of the principal ones. But in some other countries neurology still holds the position as a comparatively disregarded new speciality.

Perhaps a few glimpses at clinical neurology of the past - an attempt at giving the mid-century status presens - and particularly a lew reflections as regards the future, will not be amiss.

The valuable work of outstanding neurologists of the last century certainly had advanced our knowledge of nervous diseases considerably. Pre-eminent amongst these stands Hughlings Jackson, a close observer and a prophetic genius, who has predicted so much of what is being discovered - or rediscovered - in our days. Yet his contributions were hardly so fully known and appreciated as they deserved, until Pick and others in this century, so to speak discovered his real dimensions. No lesser man was Charcot, whose achievements are too well known to need mentioning here. Erb, beside his elucidation of the reaction of degeneration, was one of the first to insist on the separation of neurology from other branches of medicine. Westphal, the first professor of neurology in Prussia, called the attention to the importance of the absent knee-jerk in tabes (Westphal's sign) thus inaugurating the study of the deep reflexes. Wernicke's studies of aphasia - close clinical observations mixed with rather exuberantly theorizing conclusions continuing the pioneer work of Broca's - are also milestones in the development of clinical neurology. It should in passing also be noted that Sigmund Freud, who won his fame in the borderland between psychiatry and neurology in his early neurological period, did some very good work in the clinic of organic neurology viz., in the field of aphasia ("einzelsinnige Aphasie") and of cerebral birth palsies, before he embarked on his great work on psycho-analysis. The merits of men like Brown-Sequard, Fritsch and Hitzig are so well known that it is enough to mention their names. 
Yet the clinical neurology of today has chiefly been built up in this century. Instead of the haphazard hunt for odd "pathognomonic signs" which during the last century and part of the present constituted the clinical examination, a systematic complete clinical examination has leen developed, allowing of a much more precise diagnosis. And the clinical examination sensu strictiori has been supplemented by new technical tests. The development has been so overwhelming that only a few things can be touched upon. Outstanding in so many respects is Babinski's work. First and foremost his observations on the plantar reflex and its pathological alterations must be mentioned already achieved towards the end of last century $(1896,1898)$. Hardly any clinical observations have ever equa!led this discovery in widereaching importance. Remarkable also for the praiseworthy shortness with which it was first described by Babinski (a feature that should be particularly noted in our days when a man's scientific qualifications too often are measured by the quantity and bodily weight of his publications rather than by their quality and scientific weight). His wonderful study of cerebellar disturbances and of pithiatism (hysteria) are also achievements of outstanding importance. Pierre Marie, Sherrington, Déjerine. Gowers, Horsley, Cushing, Henschien, Kinnier Wilson, Foerster, von Economo, Sachs and others represent milestones in the development of neurology, just to mention a few amongst the neurologists who have passed away *. The work of Castex on the deep reflexes I particularly wish to call attention to as it is too often overlooked even by people who have made a particular study of these reflexes **.

With the advent of a more systematic clinical examination and the supplementary methods of lumbar and cisternal puncture, myelography, air-encephalography, angiography, electro-encephalography and electromyography our diagnostic ability has increased enormously and as a consequence of this the cases in a modern neurological clinic are widely different in nature from the cases admitted to the same clinics half a century ago. Then the bulk of the cases represented well advanced classical conditions whilst today the early and not always well defined clinical pictures are in overwhelming majority.

With our improved methods of examination - including air-encephalography, angiography and electro-encephalography - enormous diagnostic advances have been made. It has even been claimed that there exist no longer any "silent areas of the brain". To a certain extent this may be

* The above list does not pretend to be complete. No doubt many more names might have been mentioned.

** Compt. Rend. Soc. de Biol., 191\%. Rev. Neurol, 1:176, 1922 (in colJaboration with Roger). 
true: once the patient is admitted to a modern neurological clinic for observation and treatment, a cerebral lesion will seldom be missed. But in a certain aspect there still are and probably always will be "silent areas". If no sufficiently pronounced subjective symptoms prompt the patient to seek medical aid, no lesion can be detected. And lesions in certain areas of the brain may sometimes assume surprisingly large proportions before the patient considers the necessity of seeing a physician.

Whilst our diagnostic powers have thus increased to an enormous extent, our therapeutic achievements have not advanced in the same degree. Yet also here considerable advances have been made. Besides the spectacular achievements in neurosurgery, which here I do not intend to deal with, I shall just mention a few outstanding points in non-surgical neurological therapeutics. The prostigmin treatment of myasthenia gravis, enabling patients, who formerly lead a dismal and useless life in constant danger of sudden exitus lethalis, to lead a normal and useful life, is perhaps the most impressive therapeutic advance. The diminution in frequency of subacute combined degeneration of the cord which has followed in the wake of the intensive liver treatment of pernicious anaemia should also be mentioned and our constantly advancing anticonvulsive treatment, where in addition to or rather in replacement of the old bromid treatment, we now have phenobarbital and hydantoinate preparations and can individualize the treatment much more effectively than before.

Other pathological conditions like disseminated sclerosis still form a sad chapter in therapeutic respect. The position as regards psycho-neuroses is also far from satisfactory. The real advances made in this field are not in proportion to the enormous bulk of literature that is steadily poured out.

Now this brings us on the time-honoured distinction between organic and functional diseases of the nervous system. That this is not a very rational distinction in scientific respect, I have tried to show years agc *. Still it has perhaps some practical advantage and at any rate it is still accepted in many quarters. What is of particular interest, is the list of disturbances that were first considered "functional neuroses" and then later by advanced clinico-anatomical research had to he transferred from the functional to the organic group. Here I shall just mention as examples paralysis agitans and dystonia musculorum deformans.

It would be naive to believe that this development has reached its final stage. Further research will no doubt continue to move the border between organic and functional diseases, and in all probability this will

* Monrad-Krohn, G. H. - On the possibility of a biological conception of so-called functional nervous disorders. J. Ment. Sc., $\Lambda$ pril, 1921. 
be moved in the same direction as hitherto, viz. transferring more and more of so-called functional neuroses to the organic group. At the same time psychical factors as etiological elements and/or more often as links in vicious circles must be taken into account and this opens the much disputed topic of psychosomatic medicine, which is about to engulf the entire clinical medicine. But this is better dealt with in conjunction with our reflexions on the future of neurology.

Certain clinical transformations of various illnesses also seem to have taken place during the first half of this century. In the first place the age incidence of acute poliomyelitis has changed considerably. In the last decades a steadily increasing number of adults fall victims to this disease. In my own clinic I have had cases between 50 and 60 years of age. A similar change as regards age incidence seems to have taken place in disseminated sclerosis; the age at onset of this illness seems to be increasing.

The opposite obtains in extrapyramidal disturbances of the paralysis agitans type. Here the change came rather suddenly with the advent of that "new disease" (?) encephalitis lethargica or encephalitis epidemica which since its appearance (or reappearance?) in 1917-1918 in the wake of that terrible influenza epidemic following the first world war, has itself undergone a strange transformation. At first, the disturbances of sleep: somnolens typus inversus (insomnia at night, somnolens during the daytime). Then a myoclonic type tapering off into an epidemic of hiccup, whereupon the acute phase of the disease seems to have disappeared altogether, leaving only the insidiously starting chronic encephalitis with mostly extrapyramidal symptems and signs.

Thanks to the more efficient antiluetic remedies neuro-lues no longer seems to be the commonest disease of the nervous system. Dementia paralytica has completely changed its clinical aspect inasmuch as the expansive grandious type, so frequent a few decades ago, is fast disappearing, the simple demented type now forming the bulk of the cases. The most common cause of polyneuritis, viz. chronic alcoholism, is no longer so overwhelmingly frequent as before, nor is, strange to say, the exaggerated deep tenderness in both calves, previously such a common feature of the clinical picture of this disease (or rather group of diseases).

The increasing frequency of recognized intracranial aneurysms is on the other hand probably only due to the development of our clinical examination. The same applies to the increasing frequency of subdural haematomata. In both these conditions angiography (Fgas Moniz) has been of signal importance. The understanding of the enormous etiological im- 
portance of anoxia is increasing, thanks to the work of Heymans, Courville, Steegmann and others* ${ }^{*}$.

The equally interesting and important chapter of aphasia is at present in a very confused and sad state. That the theoretical constructions based on the first brillant observations of Broca's and Wernicke's were too simple, was soon recognized (Hughlings Jackson, Pierre Marie, Goldstein) - just to mention a few outstanding names). As regards the clinical observations of these conditions, Hughlings Jackson's saying "the aphasic patient is speechless but not wordless" has been further elaborated by Pick in his brillant studies of agrammatismus. Besides the grammatical element of speech, which thanks to Pick is now recognized as being of equal importance as the mere element of vocabulary, another element viz. the prosodic quality of speech is still being sadly neglected. If not of the same importance as the grammatical element, it diserves attention **. The rather naive placing of speech centres based mainly on speculative and unwarrantedly simplified reasoning is gradually losing ground. And critical workers in this difficult field more and more avoid the terms "speech centres", but speak instead more cautiously of "aphasic zones", lesions of which are particularly apt to cause aphasias of different shading. In other words, on the aphasic front neurology has had to beat retreat and the whole chapter of aphasia is at present in the melting pot. For the necessary enormous research work of clinic-anatomical correlation, much more complete clinical examinations are needed $* *$.

The future of neurology will be largely dependent on the program laid up by its leaders both as regards research and as regards the practice of clinical neurology. The amalgamation of clinical neurology with neuroanatomy and neuro-physiology, already so promisingly begun, should be intensified - and intensified in a harmonious way. There must be complete balance between clinical and experimental research. On the one hand the experimental animals must be subjected to the same complete painstaking and systematic examination as are the human patients, and on the other hand there must be found means for more extended anatomo-clinical

* A very instructive case I have myself demonstrated at the German Neurological Congress in Stuttgart, 1951. A report of the case will soon appear in Acta Psychiatrica et Neurologica.

** I have tried to draw attention to this important element in several articles: The prosodio quality of speech. Acta Psychiat. et Neurol., vol. 22, fasc. 3-4, 1947; Dysprosody or altered melody of language. Brain, 70:405, 194\%.

** A step in this direction I have tried to suggest in my "Clinical Examination of the Nervous System". Those interested in aphasia will benefit by reading Conrad's article: Aphasia, Agnosia, Apraxia. Fortschr. d. Neurol., Psychiat, July 1951. 
correlation based on equally complete clinical and anatomical post mortem examinations. In many countries this requires more hospital accommodation than at present available. Also proportionate stress must be placed on clinical and experimental results. One must neither neglect the experimental nor the clinical work. In the latter case one would return to an absolete stage similar to that of which Söderbergh sarcastically wrote: "Ein Zeitalter, wo man ein guter Neurologe nach zweijährigen Mikroskopieren des Nervensystems der Katze wurde" ". The careful study of Homo sapiens must not be left in the lurch for the sake of the cat.

The most urgent goal for future clinical neurology is this: We must be able to attend more fully than hitherto to the therapeutic consequences of our diagnostic results. Re-education has long been practized and the splendid work of Frenkel in the last century and Foerster in this should not be forgotten, even if at present it is somewhat overshadowed by more recent publications. It is more and more being realized that our ultinate goal is not only to cure the patient but give him back to the community in such a shape that he can enter it as a useful member. This rehabilitation in many cases means schooling for an occupation different from the one before the illness. If clinical neurology in the future does not go in more extensively for treatment and rehabilitation it will rightly be considered a sterile branch of medicine, lagging sadly behind its sister discipline, psychiatry, with its exuberant, if not always scientifically so well based therapeutic attempts.

As regards rehabilitation the problem of the numerous war invalids forced a question on the authorities which had formerly been sorely neglected, viz. the re-establishment of the invalid as a working citizen of the community. Very often a change of occupation is needed and this should be decided on the strenght of a careful neurological examination as early as possible. For this purpose the neurological clinics must be fitted out with the proper means, preferably have schools and workshops of their own at their disposal. For this purpose neurology must claim much more well equipped hospital accommodation than at present available. Here Pierce Bailey, Baker, Brown and others of the Veterans Administration of U.S.A.* ${ }^{*}$ have made splendid efforts during and since the last war. Also in England good work has been done (Guttmann and others). This must be continued and enlarged and the good example must be followed in other countries.

* Cfr. Gotthard Söderbergh's delightful article "Neurologische Sottisen". Nord. Med. Ark., 2:1-6, 1916.

** Bailey, P. - Neurological rehabilitation. Neurology, November-December, 1951. 
In this connection one must emphasize the responsability of ciinical neurology towards the victims of poliomyelitis and cerebral palsy. In both these complaints the judicious treatment is to that extent dependent on the exact diagnosis and judicious mapping out of the neurological defects in each case, that neurological guidance in their treatment and habilitation should be a matter of course.

Both on the diagnostic and therapeutic side neurology must also take up the problems of psycho-somatic medicine. This new catchword signifies a very old point of view which was not unknown to the old family physician, but which was rather pushed in the background during the decades of the most intense development of laboratory work and technical methods of medicine. Now it is coming into its own again and in danger of being overemphasized in certain quarters.

It is defined in various ways. To some it just means a group of diseases which are supposed to be caused by psychic factors. To others it means much more than that. In my opinion it comprises: 1) the study of those psychic reactions which may accompany most somatic illnesses, and which very often establish a vicious circle; 2) the study of those psychic processes which may be of etiological importance for some somatic complaints; 3) the study and utilization of therapeutic possibilities which the above studies have elucidated with the following aims in view: breaking of vicious circles mentioned above (point 1); prophylaxis and neutralizing of etiologic psychic processes (point 2); psychic preparation for and support duriag rehabilitation.

Now this applies to the whole of clinical medicine and is, as pointed out in a leading article *, not a speciality but a point of vicw. It is, as already suggested, a point of view which in various branches of medicine - and also in neurology - has been somewhat neglected during that period of really impressive development of technical diagnostic measures which we have witnessed during the last decades. It merits attention and should be taken up again for study and research in all fields of neurology. For successful treatment its consideration is a necessity.

There is no doubt that the unfortunately nearly extinct species called the familly physician of former times knew more of psychosomatic medicine than we do, in spite of the fact that the very name (psychosomatic medicine) was unknown to him. As regards the name, however, I cannot agree with the conclusion of the above-mentioned leading article * that "psychosomatic" is an unnecessary term, and the sooner it is dropped from the current literature the better. On the contrary, it is a good term emphasizing an old and forgotten point of view, which is very useful,

* Brit. M. J., Novenber 10, 1951. 
and which needs further study. A counterweight against a too onesided physiological point of view: unless the patient's psyche is carefully considered in every case, one sins against the old dictum Nihil humanum a me alienum puto.

These few remarks of mine will, I hope, give some food for reflection regarding the future of neurology. Its fate depends to a great extent on the sagacious planning by its leaders. Professor Barraquer Ferré has, beside his many personal merits, the advantage of belonging to a "neurological dynasty", taking over valuable traditions from the previous generation, enriching them and handing them over to the next, thus being more responsible than most of us for the continuity of neurology and the planning of the future. Therefore I thought it fit to choose the topic, here dealt with, in a publication issued in his honour at his 65th. birthday. Quod bonum, felix faustumque sit.

Rikshospitalets Nevrologiske Avdeling -- Oslo, Norge. 